\title{
Distribution of lung inflammation during assisted mechanical ventilation with titrated end-expiratory transpulmonary pressures in experimental acute respiratory distress syndrome
}

Thomas Kiss' ${ }^{1}$, Thomas Bluth ${ }^{1}$, Anja Braune ${ }^{1}$, Luigi Vivona ${ }^{1,2}$, Robert Huhle', Marcelo Gama de Abreu ${ }^{1}$

'Department of Anesthesiology and Intensive Care Medicine, Pulmonary Engineering Group, University Carl Gustav Carus, Technische Universität Dresden, Germany

${ }^{2}$ Department of Anesthesia and Intensive Care, University of Naples, Naples, Italy

\section{Background}

Evidence of lung injury due to spontaneous breathing activity $(\mathrm{SB})$ in acute respiratory lung injury (ARDS) has been obtained during inappropriate settings of positive endexpiratory pressure (PEEP) and artificially high respiratory drive. In this study, we investigated the correlation between PEEP set according to transpulmonary pressure (TP) and assisted SB in experimental severe adult respiratory distress syndrome (ARDS) in pigs. We hypothesized that in experimental severe ARDS, assisted SB with positive endexpiratory TP in all lung regions, as compared to negative TP, reduces lung inflammation measured by Fluor-18deoxyglucose and positron emission tomography (PET).

\section{Methods}

In 12 anesthetized pigs, custom-made intrapleural pressure sensors were placed in non-dependent and dependent lung regions by video-assisted thoracoscopy. Experimental severe ARDS was induced by saline lung lavage and injurious high tidal volume mechanical ventilation, until $\mathrm{PaO}_{2}$ $<100 \mathrm{mmHg}$. Following a lung recruitment maneuver and a decremental PEEP trial $\left(26 \mathrm{cmH}_{2} \mathrm{O}\right.$ to $6 \mathrm{cmH}_{2} \mathrm{O}$ by steps of 2 $\mathrm{cmH}_{2} \mathrm{O}$ ), respiratory system mechanics and regional TP were determined at each PEEP level (Figure 2). The bestPEEP level was defined as the lowest PEEP yielding positive end-expiratory TP in all lung regions. Animals were then randomly assigned to airway pressure release ventilation with best PEEP $+4 \mathrm{cmH}_{2} \mathrm{O}$ (Group 1, "SPONT +", $\mathrm{n}=6$ ) or best PEEP $-4 \mathrm{cmH}_{2} \mathrm{O}$ (Group 2, "SPONT -", $\mathrm{n}=6$, Table 1). SB was induced (proportion of SB being 40 to $60 \%$ of total minute ventilation) gas exchange, hemodynamics and lung mechanics were assessed for a time period of 12 hours (Figure 1). At the end lung inflammation was determined as the specific uptake rate (KiS) of Fluor-18-deoxyglucose using PET (Patlak model), as normalized by tissue blood (Sokoloff model), as well as gas fraction (computed tomography).

\section{Results}

There were no significant differences in bodyweight and age. A two tailed Mann Whitney $U$ test showed a significantly lower KiS for the high PEEP group (Figure 3). Repeated measures two-way ANOVA revealed no differences between groups for hemodynamics, gas exchange and lung mechanics. The best- PEEP level did not differ significantly from the PEEP level resulting in lowest lung elastance.

\section{Conclusion}

In this model of severe ARDS in pigs, assisted SB with regional TP levels titrated to avoid collapse at end-expiration, importantly attenuated lung inflammation.

\section{References}

Güldner A, Braune A, Carvalho N, Beda A, Zeidler S, Wiedemann B, et al. Higher levels of spontaneous breathing induce lung recruitment and reduce global stress/strain in experimental lung injury. Anesthesiology. 2014 3:673-82.

\section{Figures \& Tables}

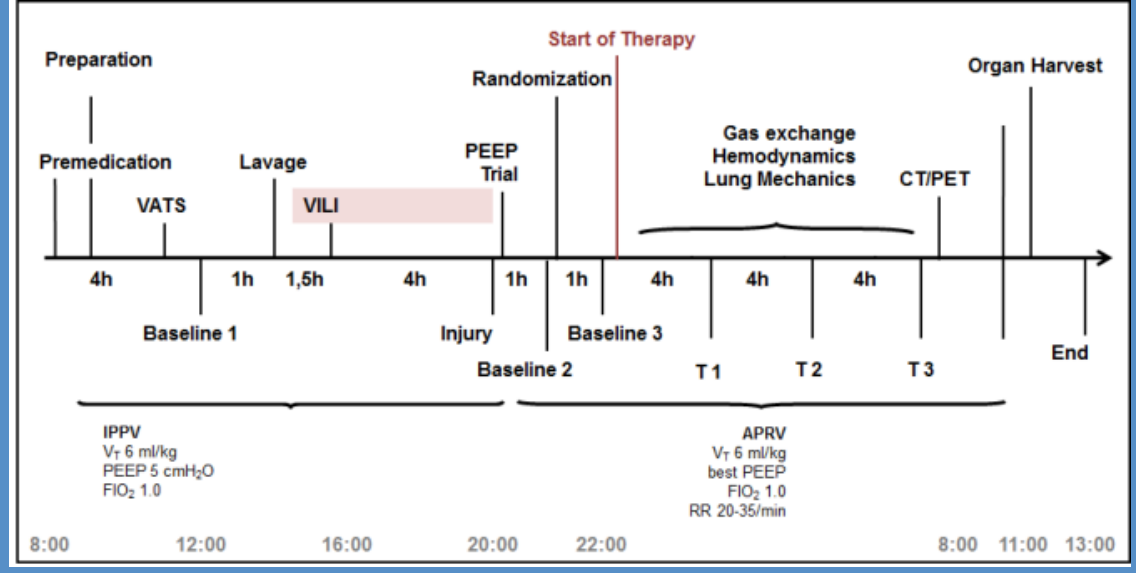

Fig.1 Time course of interventions VATS, video assisted thoracoscopy, induced lung induced lung
injury injury

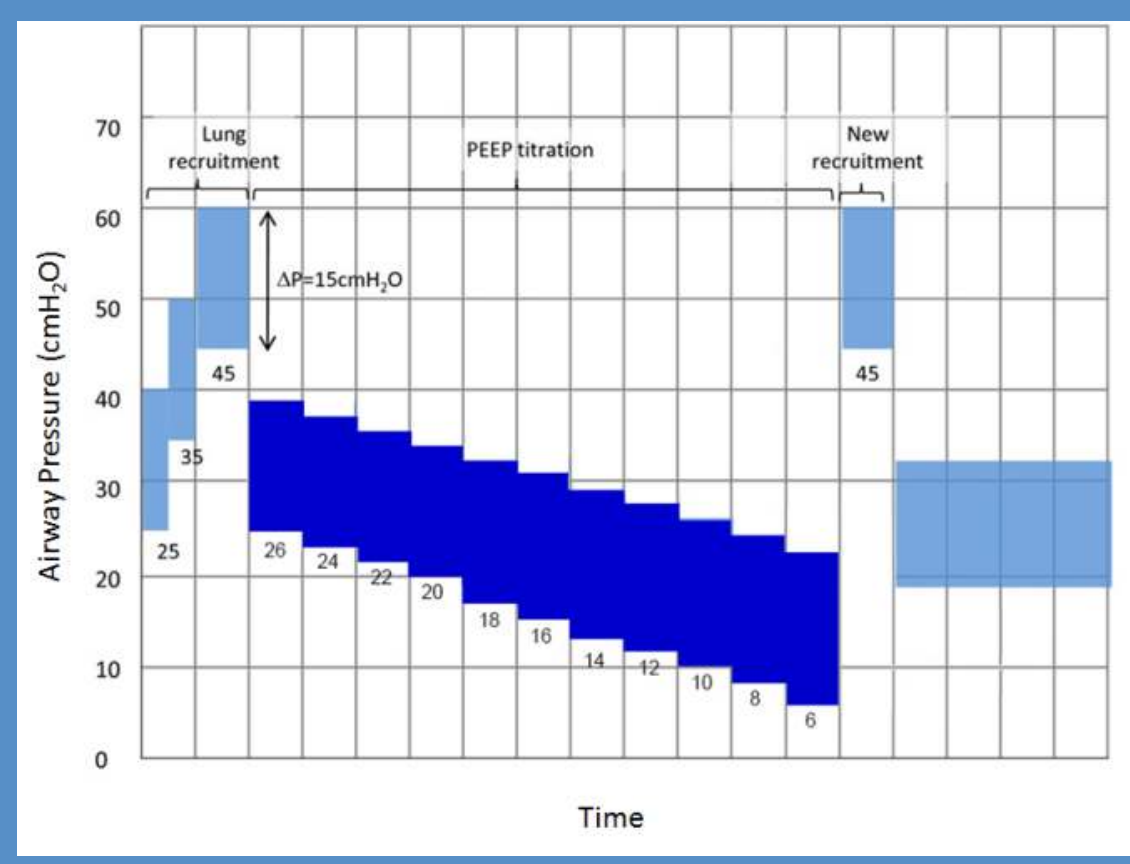

Fig.2 Recruitment maneuver, followed by the decremental PEEP (positive end-expiratory pressure) trial, new recruitment maneuver

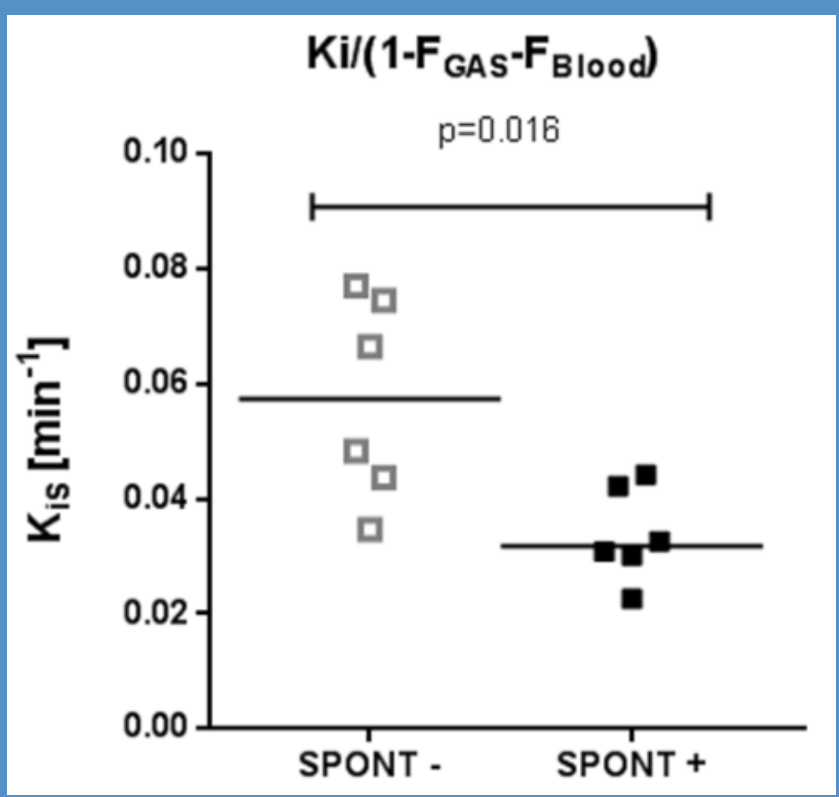

Fig.3 Specific uptake rate (KiS) of Fluor-18-deoxyglucose using positron emission tomography. Significantly lower KiS for the high PEEP group (SPONT,$+ n=6$ ) compared to the low PEEP group (SPONT -, n=6). MannWhitney test.

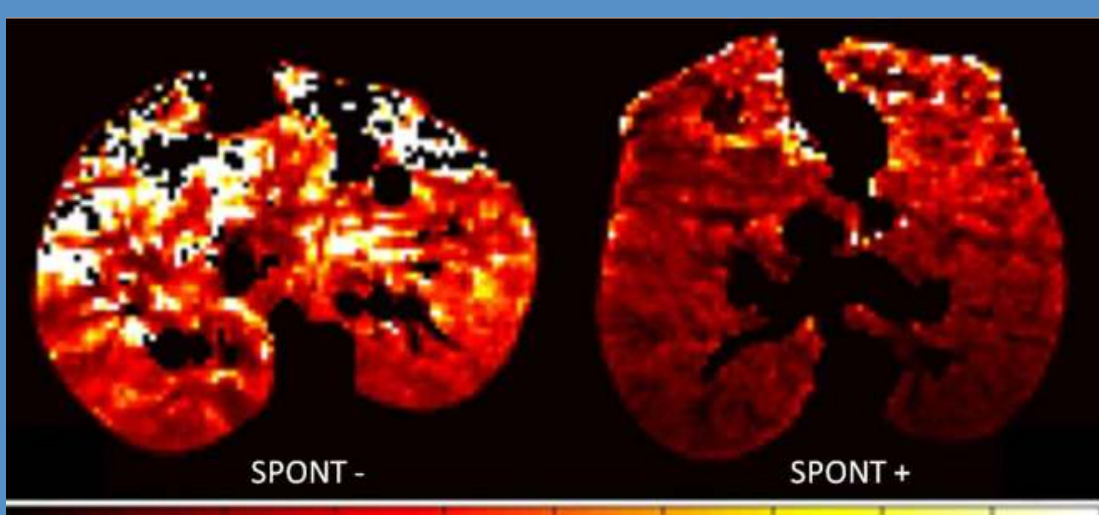

Fig.4 Specific uptake rate (KiS) of Fluor-18-deoxy-glucose using positron emission tomography measurements in two representative animals. The color bar reaches from black to white $(\mathrm{KiS}=0,0$ to $0,2 \mathrm{ml} / \mathrm{min} / \mathrm{g}$ ).

\begin{tabular}{|c|c|c|c|c|c|c|}
\hline & & BL3 & $\mathrm{T1}$ & $\mathrm{T} 2$ & T3 & \\
\hline \multirow{3}{*}{ SPONT + } & ass & $2.3 \pm 2.6$ & $3.1 \pm 1.4$ & $3.4 \pm 0.9$ & $3.7 \pm 0.7$ & $\mathrm{cmH}_{2} \mathrm{O}$ \\
\hline & con & $1.0 \pm 2.2$ & $3.8 \pm 0.7$ & $3.5 \pm 0.9$ & $3.8 \pm 0.6$ & $\mathrm{cmH}_{2} \mathrm{O}$ \\
\hline & spo & $6.0 \pm 4.7$ & $3.2 \pm 1.7$ & $3.9 \pm 1.7$ & $3.8 \pm 1.5$ & $\mathrm{cmH}_{2} \mathrm{O}$ \\
\hline \multirow{3}{*}{ SPONT - } & ass & $-2.4 \pm 2.1$ & $-1.9 \pm 1.9$ & $-2.1 \pm 1.5$ & $-1.6 \pm 1.7$ & $\mathrm{cmH}_{2} \mathrm{O}$ \\
\hline & con & $-1.2 \pm 1.7$ & $-2.2 \pm 2.0$ & $-2.3 \pm 1.2$ & $-1.9 \pm 1.8$ & $\mathrm{cmH}_{2} \mathrm{O}$ \\
\hline & spo & $-0.4 \pm 4.0$ & $-1.5 \pm 1.4$ & $-0.4 \pm 2.1$ & $-0.5 \pm 2.3$ & $\mathrm{cmH}_{2} \mathrm{O}$ \\
\hline \multicolumn{7}{|c|}{$\begin{array}{l}\text { Table 1. Endexpiratory transpulmonary pressures of caudal pleural sensor } \\
\text { at BL3 (start of therapy), Time } 1 \text { ( } 4 \text { hours after start of therapy), Time } 2 \text { ( } 4 \\
\text { hours after Time 1) and Time } 3 \text { ( } 4 \text { hours after Time } 2 \text { ) expressed as } \\
\text { mean } \pm \text { standard deviation. Ass, assisted breaths; con, controlled breaths; } \\
\text { spo, spontaneous breaths }\end{array}$} \\
\hline
\end{tabular}

